\title{
Public funding of Higher Education: who gains, who loses?
}

\author{
Ana Balcão Reis \\ Faculdade de Economia da Universidade Nova de Lisboa, ${ }^{* \dagger}$
}

August 2010

\begin{abstract}
This paper analyses the effects of public funding of higher education on the welfare of the different agents. It takes into account the hierarchical nature of the educational system and also the fact that parents always have the possibility to complement basic public education with private expenditures in individual tutoring.

It is obtained that although public funding implies a larger access to higher education it is always the case that some of the agents that gain access lose in welfare terms. Moreover, it is shown that the marginal agent to access university would always prefer a pure private funding system. Thus, when studying the effects of public funding of higher education, we can not identify gaining access to University with an increase in welfare.

Finally, I consider a funding system where only those that send their offspring to university support the funding of higher education.

Keywords: higher education, public funding

JEL Classifications: I22 and I28
\end{abstract}

*email: abr@fe.unl.pt

†I acknowledge financial support from FEDER through the Fundação para a Ciência e Tecnologia. I thank Tiago Neves Sequeira for many comments and suggestions. I thank Nicholas Barr and the other participants on the Arne Ryde Symposium on "The Economics of Higher Education", and participants on the ASSET 2007, for their comments. 


\section{Introduction}

For OECD countries the average value for public expenditure on higher education as a percentage of GDP was in 2006, $1.3 \%$, with a minimum of $0.6 \%$ for Japan and a maximum of $2.3 \%$ for Denmark. ${ }^{1}$ Only recently the "no tuition" policy followed in many European countries has been questioned and the public funding of higher education is under debate. However, since the initial contribution of Hansen and Weisbrod (1969), a consensus was built in the economic literature that public funding of higher education implies a redistribution of income from poor to rich people, or at least from the ends (both poor and rich) to the middle. This is mainly a consequence of the fact that students from high income families are more likely to attend higher education.

Barr (2004) presents data for 2002 from the UK Education and Skills Select Committee: "81 per cent of children from professional backgrounds went to University; the comparable figure for children from manual backgrounds was 15 per cent". For the US, Carneiro and Heckman (2002) also show that college participation rates are much higher for high income families. ${ }^{2}$ The recent study Eurostudent 2005, that considers several European countries, shows that in general the percentage of students' parents with higher education is much higher than the corresponding percentage for the whole population. ${ }^{3}$ Thus, the large amounts governments all around the world keep spending on higher education seem to imply a redistribution in the wrong direction.

This paper aims to study the effects of the public funding of higher education on the welfare of the different agents, focusing on those agents whose decision of sending or not their child to th University depends on public funding policy. ${ }^{4}$ To this end, I compare different levels of higher education subsidies taking into account the hierarchical nature of the educational system and also the fact that parents always have the possibility to complement public education with private expenditures in individual tutoring. I establish the characteristics of those agents whose welfare increases and those agents whose welfare decreases with the public funding of higher education. I consider pure private funding, pure public funding and a mixed system where a percentage of the University cost is privately supported with the remaining being publicly supported. Note that what is relevant for the results in this paper is not who is the provider of higher education but who finances it. Public funding is financed by income taxes that apply to the whole population.

There are already many papers that use a Political Economy approach to study how the public funding of higher education may be the result of the politi-

\footnotetext{
${ }^{1}$ OECD 2009. See also Greenway and Haynes (2004) for a detailed description of the data relative to higher education.

${ }^{2} \mathrm{Su}(2004)$ refers to several studies for the US and the UK for the 70's and 80's where this is shown: Hansen (1970), Radner and Miller (1970), Peltzman (1973), Bishop (1977) and Le Grand (1982).

${ }^{3}$ The only exception is Ireland. This study collects several indicators that describe the social and economic conditions of higher education students in Europe. Unfortunately there is almost no data on parents' income.

${ }^{4}$ To simplify the exposition I don't distinguish between higher education and university.
} 
cal process. Important examples are Creedy and François (1990) and Fernández and Rogerson (1995). Here, however, I follow the Gloom and Ravikumar (2003) approach, who take policy as given and look at its implications.

De Fraja (2002) gives a complete theoretical characterization of the most efficient funding of higher education. However, he is not worried with the questions asked in this paper relative to access and welfare. Closer to the questions addressed in this paper, Caucutt and Kumar (2003) study the effects of increasing higher education subsidies on inequality, welfare and efficiency. They solve their model numerically for the US case and obtain that, when present, the aggregate welfare gain is minimal. They also calculate the welfare gain for the two types of agents present in their model: poor (school educated) and rich (college educated). In any of the policy alternatives studied the rich lose and the poor gain. This would indicate that subsidizing higher education benefits the poor, implying a redistribution in the right direction, which goes against the literature consensus. However, this is again an aggregate measure, in this case for all parents of a given type, obtained as an expected gain from the policy and without discriminating between those who send their child to college and those who don't. In this paper, I calculate the welfare gain for each of a continuum of different parents distinguishing between those who decide to send their child to the University and those who decide not to send. I focus exactly on those whose decision depends on the subsidy level. The simplicity of the model allows to obtain general analytical results.

I take into account the hierarchical nature of the educational system. Although usually absent from economic analysis, this aspect is very important for the study of higher education as it implies that only those that attain a minimum level in basic education are able to go to the University. ${ }^{5}$ Thus, higher education is never a good of universal access, even if it is free. For OECD countries in 2007, the average value of the entry rate was $56 \%$ for type-A tertiary education and $15 \%$ for type-B tertiary education (OECD 2009). The access to higher education is always limited and there is evidence that the main barrier in the access to University is not the lack of financial means but the failure to attain the educational prerequisites required to access University.

"...ample evidence from the United States suggests that true credit constraints are not a binding issue in the admission to higher education in the vast majority of cases (cf. Carneiro and Heckman 2003; Cunha et al. 2006). Rather, the fact that students from disadvantaged family backgrounds have a much lower probability of entering University seems to be caused by a lack of early educational investments which deprive these students of the basic prerequisites to advance to University. If this is true in the United States, where

\footnotetext{
${ }^{5}$ Judson (1998), Su (2004) and Blankenau (2005) are exceptions that consider the hierarchical nature of education. However, all these papers study the allocation of public funds across different levels of education. This is not the problem addressed here. In this paper expenditures in basic education are taken as given and I analyze the welfare implications of public expenditure on higher education.
} 
colleges and universities charge substantial private fees, then it seems that it is even more relevant in Europe, where higher education is mostly publicly funded" in Woßmann and Schutz (2006, page 24)

Carneiro and Heckman (2002) obtain that "at most $8 \%$ of American youth are subject to short-term liquidity constraints that affect their post-secondary schooling". 6 According to these authors, the main justification for the income gap in enrollment is long-term factors related to the parental environment. For Australia, Cardak and Ryan (2009) obtain that what explains the socioeconomic gap in participation in higher education is the gap in finishing secondary education or, for those students that complete secondary education, the dependence of the secondary education final grade on students socio-economic background. The secondary education final grade determines if the student is eligible to attend University.

These empirical findings motivate a crucial assumption of the model presented in this paper, that there is a threshold level of human capital that must be attained for students to be able to advance to higher education. This assumption will have important implications for the comparison between the different funding systems.

In this paper, basic education is free and of universal access but parents have the choice to complement public basic education with private expenditures in individual tutoring or private classes. Thus, in what refers to basic education I follow Epple and Romano (1996) in considering that public funding may be supplemented by private-market purchases. This private expenditure may be used to obtain access to higher education even in a public funding environment.

Finally, a remark to say that this paper is about the funding of higher education, the arguments developed here do not apply to the funding of research conducted by universities. Also, I do not look at public funds spent on basic education or at policy decisions related to the quality of basic education. I focus on higher education taking as given the outcomes of basic education.

Section 2 presents the model, section 3 compares different funding systems in what refers to access to higher education. Section 4 looks at welfare. Section 5 considers an alternative funding system that approximates a higher education tax. Section 6 concludes.

\section{The model}

Each agent has one offspring whose education he decides taking into account her ability. Agents are heterogeneous in what refers to the level of human capital they receive from their parents and also to the ability with which they are born.

There are two levels of education: basic $(B)$ and University $(U)$. The access to basic education is universal (and free) but only those who attain a predefined threshold are able to advance to University. So, the model takes into account

\footnotetext{
${ }^{6}$ They emphasize that their results must be due to the system of financial aid to support post-secondary education that is in place in the US.
} 
the hierarchical nature of the educational system (see for instance Su, 2004 and Judson, 1998). In what refers to higher education I consider three alternatives: pure private funding, pure public funding and a mixed system where part of the cost is privately supported. Note that the distinction between public and private higher education refers only to who pays for it. ${ }^{7}$

The utility of agent $i$ depends on own consumption and on the level of human capital of his offspring $\left(h_{+1}^{i}\right)$.

$$
u^{i}=\ln c^{i}+\rho \ln h_{+1}^{i} \quad, \rho>0
$$

This follows de la Croix and Doepke (2004) and is equivalent to Gloom and Ravikumar (1992). As usual in the literature I consider that each individual income is given by his level of human capital. ${ }^{8}$ All decisions are made by adults.

The accumulation of human capital depends on the parent's level of human capital and on the offspring's ability $(z)$. I assume that ability is known at the moment the decision is taken of advancing or not to higher education. This is in line with de Fraja (2002), who considers that there is uncertainty on ability but the realization is known before higher education choices are made. After basic education, to which all children attend, the level of human capital is given by:

$$
h_{+1}^{B}=z h^{\delta}, \quad 0<\delta<1
$$

where I omitted the index $i$ to simplify notation. ${ }^{9}$ The level of human capital of the offspring depends on the parent's level of human capital. This assumption is usual in the literature and it is deeply founded on empirical findings (see for instance, Carneiro and Heckman, 2003).

If this level of human capital is higher than a predefined threshold $\widehat{h}$, then the agent may decide to send the offspring into University. Otherwise, the offspring does not fill the needed prerequisites to advance to University and $h^{B}$, given in (2), is the final level of human capital that she takes to the next period unless, as explained below, parents invest on private tutoring. The existence of a minimum threshold is an important assumption of the model. This is a characteristic that distinguishes higher education from basic education.

If the offspring goes into University, then the level of human capital she will have as an adult is $h^{U}$, given by:

$$
h_{+1}^{U}=\gamma z h^{\delta}=\gamma h_{+1}^{B}, \quad \gamma>1
$$

$\gamma$ is the productivity parameter in higher education. It is larger than one as higher education builds on the outcome of basic education.

Parents have also the possibility of complementing public basic education with private tutoring, $e$, in order for the offspring to attain the threshold level

\footnotetext{
${ }^{7}$ All universities are equal as I abstract from quality considerations.

${ }^{8}$ See for instance Gloom and Ravikumar $(1992,2003)$ or de la Croix and Doepke (2004). In what refers to the utility function, including the human capital of the offspring is equivalent to assuming that parents value the wealth they pass to their children. On this, see footnote 2 in Gloom and Ravikumar (1992).

${ }^{9}$ Considering diminishing returns to ability would not change the results of the model.
} 
$\widehat{h}$ that determines the possibility of attending University. The level of human capital attained by combining basic education with private tutoring $\left(h^{e}\right)$ is given by,

$$
h_{+1}^{e}=(1+\varepsilon e) z h^{\delta}=(1+\varepsilon e) h_{+1}^{B}
$$

where $\varepsilon$ is a productivity parameter for private tutoring. As is the case with higher education, tutoring builds on the outcome of basic education. This formulation implies that for any $e>0$ we obtain $h^{e}>h^{B}$.

I assume that the only role of tutoring is to allow the access to the University but that it does not change the return to education once the student sits in University classes. ${ }^{10}$ Thus, when the agent incurs this expenditure he chooses the exact amount that allows the attainment of the threshold, $h^{e}=\widehat{h}$. So, from (2) and (4), tutoring is given by:

$$
e=\frac{\widehat{h}-h_{+1}^{B}}{\varepsilon h_{+1}^{B}}=\frac{\widehat{h}-z h^{\delta}}{\varepsilon z h^{\delta}}
$$

According to (5) the cost of the necessary private tutoring decreases with the student ability and with the parent human capital. If these are too low it becomes too expensive to pay for the private tutoring.

Thus, after all the decisions related to education, the offspring's human capital will be,

$$
h_{+1}=\left\{\begin{array}{cr}
h_{+1}^{B}=z h^{\delta} & \text { if the offspring does not go into University } \\
h_{+1}^{U}=\gamma z h^{\delta} & \text { if the offspring goes into University }
\end{array}\right.
$$

Note that choices about the level of education are discrete, a student may do only basic school or she may go on to University, but if going to University she graduates. ${ }^{11}$ Also, quality choices are not considered, all basic education is equal, all higher education is equal.

To study the agents' choices I now look at the costs of higher education. The following sections consider pure public, pure private and mixed funding of higher education and compare the results in what refers to access and welfare.

\section{Funding and Access to higher education}

I begin this section by characterizing separately the different funding systems, then I compare these systems in terms of the access to higher education.

\footnotetext{
${ }^{10}$ Tutoring could always increase the child final human capital or, alternatively increase the final human capital of all students who go into the University. In any case, the model qualitative results would not change as the important point is that there are always some agents who make an extra investment as a means to gain access to the University.

${ }^{11}$ Galor and Zeira (1993) have shown that the characteristic of indivisibility of human capital investment in the presence of credit market imperfections implies that the initial distribution of wealth affects aggregate output and investment in the short and the long run. In this paper there are implicit credit market imperfections as agents may only spend current income.
} 


\subsection{Pure public funding}

When there is pure public funding, higher education is free for private agents and is paid by the government with the revenues of a proportional income tax at rate $\tau$. Thus, in this case the budget constraint of any given agent is:

$$
c=(1-\tau)(h-e)
$$

where education expenditures are taken to be tax deductible. ${ }^{12}$ All the decisions are taken by parents. Students accumulate human capital according to parents' decisions. Parents maximize utility (1) subject to (7) and the education technology defined by (6), the threshold $\widehat{h}$ and the possibility of private tutoring as described by (5). Agents take $\tau$ as given. ${ }^{13}$

There are three types of solutions. In the first one, which I label $U$, the student is able to go to the University without the need of private tutoring. A second type of solution, which I label $U T$, happens when after basic education the student does not attain the threshold $\widehat{h}$ but the parent pays private tutoring in order for the student to advance to University. Finally, the last type of solution, which I label $B$, happens when the student does not go to the University, so her final level of human capital is the one that results from basic education. When possible, $U$ is the best solution. In this case it is always optimal to send the student to the University, as there are no additional costs. ${ }^{14}$ When $U$ is not possible, which solution - $U T$ or $B$ - maximizes utility depends on the characteristics of the agent, namely income and student's ability.

The next table characterizes the three types of solutions, where the subscript $G$ stands for a solution in the context of pure public funding.

Table 1: solutions with pure public funding of higher education

\begin{tabular}{|llll|}
\hline & $U^{G}$ & $U T^{G}$ & $B^{G}$ \\
$c$ & $(1-\tau) h$ & $(1-\tau)(h-e)$ & $(1-\tau) h$ \\
$h_{+1}$ & $h_{+1}^{U}=\gamma h_{+1}^{B}$ & $h_{+1}^{U}=\gamma h_{+1}^{B}$ & $h_{+1}^{B}=z h^{\delta}$ \\
\hline
\end{tabular}

Any parent may be characterized by a value for his income, $h$, and a value for his offspring ability, $z$. Thus, we may define in the space $(h, z)$ regions where the corresponding agents have optimal solutions of types $U, U T$ or $B$.

If $h_{+1}^{B} \geq \widehat{h}$, that is, if after basic education the minimum threshold $\widehat{h}$ is attained, then, $U$ is possible. In this case, $U$ is always the optimal choice. From (2) this implies that an agent sends his offspring to the University without paying any private tutoring if:

$$
z \geq \frac{\widehat{h}}{h^{\delta}}
$$

\footnotetext{
${ }^{12}$ Note that the agent is not able to use the returns to investment on education as these belong to the offspring. So, there are implicit credit market imperfections in the model.

${ }^{13}$ In equilibrium $\tau$ must be such that tax revenues are equal to expenditure on higher education. I will come back to this point below.

${ }^{14}$ There might be opportunity costs if the student could be working instead of studying. I do not consider these opportunity costs. Maintenance costs may be included in the tuition, as long as they are independent of income and ability.
} 
For those agents who don't satisfy the above condition the choice is between solutions $U T$ and $B$. The agent chooses to pay for private tutoring if utility for solution $U T$ is higher than utility for solution $B$. Taking into account the utility function (1) and the values for consumption and human capital as described in Table 1, we obtain that:

$$
u\left(U T^{G}\right)>u\left(B^{G}\right) \Longleftrightarrow(h-e) / h>\gamma^{-\rho}
$$

Substituting with the value of tutoring as determined in (5), we obtain that the agent pays private tutoring, $e>0$, and sends the offspring to University if (8) is not verified and:

$$
z>\frac{\widehat{h}}{h^{\delta}}\left[\varepsilon \frac{\gamma^{\rho}-1}{\gamma^{\rho}} h+1\right]^{-1}
$$

Below this line agents don't send their offspring to the University. As the second term in the right side of (10) is a positive number smaller than one, this curve is always below the curve defined in (8). Figure 1 shows the regions that correspond to each type of solution.

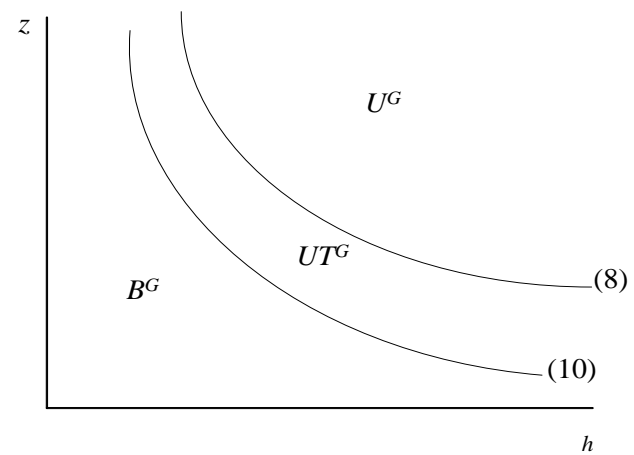

Figure 1: Agents' choices under pure public funding

$U^{G}$ refers to agents who send their offspring to the University without tutoring, $U T^{G}$ refers to those who pay for tutoring and $B^{G}$ refers to agents who don't send their offspring to the University.

\subsection{Mixed and pure private funding}

In the case of mixed funding the tuition covers part of the University cost, the remaining being supported by the public budget. In the case of pure private funding the tuition covers the whole University cost. All universities have the same cost $x$ and imply the same return to education as defined in (3). So, I abstract from considerations related to the choice of quality in higher education. Let $\phi$ be the percentage of total University costs that is supported by the tuition, so that an agent that sends his offspring to the University pays $\phi x_{t} \cdot{ }^{15}$

\footnotetext{
${ }^{15}$ If maintenance costs are included in the fixed University cost, $x$, then pure public funding includes grants that cover these maintenance costs and the case of no grants but zero tuition corresponds to a mixed funding case, with positive $\phi$.
} 
The next table characterizes the three types of solutions, where the subscript $M$ stands for a solution in the context of mixed (private and public) funding.

Table 2: solutions with mixed funding of higher education

\begin{tabular}{|llll|}
\hline & $U^{M}$ & $U T^{M}$ & $B^{M}$ \\
$c$ & $\left(1-\tau_{\phi}\right)(h-\phi x)$ & $\left(1-\tau_{\phi}\right)(h-e-\phi x)$ & $\left(1-\tau_{\phi}\right) h$ \\
$h_{+1}$ & $h_{+1}^{U}=\gamma h_{+1}^{B}$ & $h_{+1}^{U}=\gamma_{U} h_{+1}^{B}$ & $h_{+1}^{B}$ \\
\hline
\end{tabular}

where $\tau_{\phi}$ is the tax rate needed to pay the part of University costs supported by the public budget, as defined below.

Definition 1 Let $\tau_{\phi}=f(\phi)$ be the level of the tax rate for a mixed funding system characterized by $\phi$, that guarantees that in equilibrium tax revenues are equal to public expenditure on higher education. $\partial f / \partial \phi<0, f(1)=0, f(0)=\tau$.

The subscript $\phi$ emphasizes the fact that the size of the tax rate depends on $\phi$. To be able to fully characterize the function $f(\phi)$ I would need to describe the distribution of $h$ and $z$, as these characteristics determine which agents continue to higher education and so, determine the total amount of higher education costs. However, it is always the case that the larger the $\phi$, the lower the tax rate, as the percentage of total costs supported by public funds decrease and it will be shown that when $\phi$ increases less students go to higher education decreasing total costs with higher education. This property is enough to derive all the results presented below. Notice that for $\phi=0$ we are back in the case of pure public funding of higher education, described in Table 1. For pure private funding $\phi=1$ and $\tau=0$, as in this case there is no need for public revenues to fund higher education.

I solve for the mixed funding of higher education and then the solution for private funding is obtained considering $\phi=1$ (and $\tau=0$ ). For both pure private funding and mixed funding of higher education, the comparison between solutions of types $U$ and $B$ implies that for agents who attain the threshold $\widehat{h}$, there is still a decision to be taken. These agents don't need to pay private tutoring but they must decide if they want to pay the tuition.

Taking into account the utility function (1) and the values for consumption and human capital for solutions $U$ and $B$, as described in Table 2, we obtain that an agent who verifies condition (8) decides to pay the tuition if:

$$
u\left(U^{M}\right)>u\left(B^{M}\right) \Longleftrightarrow(h-\phi x) / h>\gamma^{-\rho}
$$

Which implies that,

$$
h>\frac{\phi x \gamma^{\rho}}{\gamma^{\rho}-1}
$$

Thus, for those agents who are able to send their offspring to the University without paying tutoring, the decision of sending or not their offspring to the University only depends on income, not on their ability. ${ }^{16}$ Only those agents

\footnotetext{
${ }^{16}$ This is the result of assuming a fixed University cost $\phi x_{t}$ and also a log utility combined with a Cobb-Douglas production function for $h$, as discussed by Gloom and Ravikumar (2003).
} 
with high enough income find it optimal to pay the tuition. For lower values of $h$ the optimal solution is of type $B$.

For those agents whose offspring do not attain $\widehat{h}$ the decision is to pay $e$ and $\phi x_{t}$ or not send their offspring to the University. As tutoring costs depend on the student's ability, $z$, for these agents the decision depends on both $h$ and $z$. For $(h, z)$ below the line defined in (8), the agent compares solutions $U T$ and $B$. Taking into account the utility function (1) and the values for consumption and human capital for these solutions as described in Table 2, we obtain that,

$$
u\left(U T^{M}\right)>u\left(B^{M}\right) \Longleftrightarrow(h-\phi x-e) / h>\gamma^{-\rho}
$$

Substituting with the value of $e$ given in (5), this implies that the agent pays private tutoring, $e>0$, and sends the offspring to University if (8) is not verified and :

$$
z>\frac{\widehat{h}}{h^{\delta}}\left[\varepsilon \frac{\gamma^{\rho}-1}{\gamma^{\rho}} h+1-\varepsilon \phi x\right]^{-1}
$$

Below this line the optimal solution is $B$; the student does not advance to higher education.

Figure 2 combines the results obtained in conditions (12) and (14) and shows the regions that correspond to each type of solution for the mixed funding case. Notice that the curve defined in condition (14) crosses the line that determines the possibility of going to the University without tutoring, defined in (8), for $h=\phi x \gamma^{\rho} /\left(\gamma^{\rho}-1\right)$, the threshold level obtained in (12). Thus, the lines defined in (12) and (14) cross the curve defined in (8) at the same point. When $\phi$ decreases the vertical line moves to the left and the curve that separates $U T$ from $B$ goes down. Thus, as $\phi$ decreases, decreasing the private contribution to University costs, access to higher education increases.

Clearly the number of agents who go to University is maximized for $\phi=0$, the case of pure public funding. Also, even if there are no private costs attached to higher education, there is a set of agents who don't advance into it. Moreover, the poorer a family is, the more likely it is that this happens. This is in line with empirical observations, namely with the conclusions of Carneiro and Heckman (2002) and Cardak and Ryan (2009) that the main justification for the income gap in the access to higher education is not short-run financial constraints but must lie on earlier educational achievements. When higher education is free, the justification for the income gap on access is related to the minimum threshold, $\widehat{h}$. This shows how relevant it is to take into account the fact that only those who attain this minimum threshold are able to advance to higher education. The reason why the likelyhood of not attending higher education is higher for the poorer is that the level of human capital of the student depends on her parent's level of human capital which determines income. In the model human capital totally determines income, in the data income is highly correlated with education. 


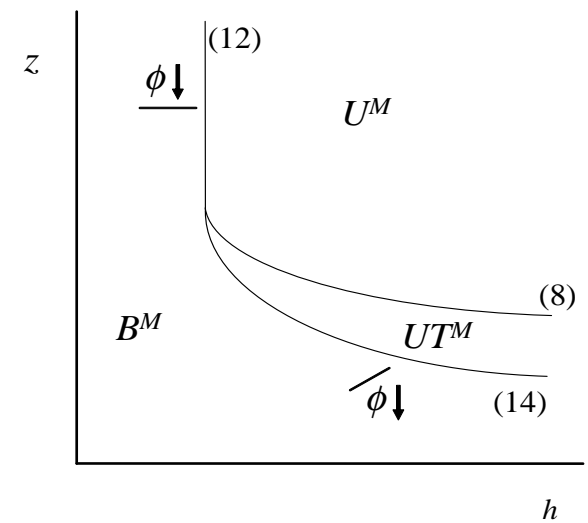

Figure 2: Agents' choices under mixed or pure private funding $U$ refers to agents who send their offspring to the University without tutoring, $U T$ to those who pay tutoring and $B$ to those who don't send their offspring to the University. If $\phi$ decreases, the vertical line moves to the left and curve (14) goes down and to the left.

Note also that the curve that determines who is willing to pay tutoring in this case, given in (14), is - for any $\phi>0$ - above the curve that determines who is willing to pay tutoring in the case of pure public funding of higher education, given in (10). This implies that when agents also have to pay the tuition they are less willing to pay tutoring and so, the set of agents who chooses to pay tutoring is smaller in this case. Moreover, the larger the tuition (larger $\phi$ ), the smaller is the set of agents who chooses to to pay for tutoring.

\subsection{Access to higher education for different values of $\phi$}

Proposition 3 looks at agents' decisions under each funding system and characterizes the set of agents who never send their offspring into University, those that always do and those for whom the decision depends on the value of $\phi$.

Proposition 2 i) Those agents characterized by a pair $(h, z)$ such that

$$
z<\frac{\widehat{h}}{h^{\delta}}\left[\varepsilon \frac{\gamma^{\rho}-1}{\gamma^{\rho}} h+1\right]^{-1}
$$

don't send their offspring to the University in either funding system.

ii) Those agents characterized by a pair $(h, z)$ such that

$$
h>\frac{x \gamma^{\rho}}{\gamma^{\rho}-1} \cap z>\frac{\widehat{h}}{h^{\delta}}\left[\varepsilon \frac{\gamma^{\rho}-1}{\gamma^{\rho}} h+1-\varepsilon x\right]^{-1}
$$

send their offspring to the University in any funding system. 
iii) For all the other agents the decision depends on the value of $\phi$. For any $\phi$, such that $0 \leq \phi \leq 1$, those agents characterized by a pair $(h, z)$ such that the conditions in i) and ii) are not verified and,

$$
h>\frac{\phi x \gamma^{\rho}}{\gamma^{\rho}-1} \cup z>\frac{\widehat{h}}{h^{\delta}}\left[\varepsilon \frac{\gamma^{\rho}-1}{\gamma^{\rho}} h+1-\varepsilon \phi x\right]^{-1}
$$

send their offspring to University.

Proof. The inequality in part i) of the Proposition is the same condition as in equation (10) but with the opposite sign and separates the sets $U T^{G}$ and $B^{G}$ in Figure 1. For $\phi=0$, this is the condition that determines which agents don't send their offspring to the University. For $\phi>0$, the relevant conditions are (14) and (12). As the set determined by these two conditions is above (10), for any $\phi>0$, those pairs $(h, z)$ that are below the line defined in (10) are also below the line defined by (14) and (12), shown in Figure 2. Thus, below this line agents don't send their offspring to the University in either system. This proves part i) of the Proposition.

In part ii) of the Proposition, the first inequality is given in (12) for $\phi=1$ and the second in (14), also for $\phi=1$. As seen above (12) results from imposing $u\left(U^{M}\right)>u\left(B^{M}\right)$, for agents who satisfy (8), and (14) results from imposing $u\left(U T^{M}\right)>u\left(B^{M}\right)$, for agents who don't satisfy (8). If a pair $(h, z)$ is above these lines for $\phi=1$ it also above these lines for any $\phi<1$. Thus, if the agent is in the region above (14) and to the right of (12) he sends his offspring to the University for $\phi=1$ and also for any $\phi<1$.

For $\phi=0$, condition (10) determines which agents send their offspring to the University. The line defined by (10) is below the line defined by (14), for any $\phi>0$. This proves part ii) of the Proposition.

Part iii) of the Proposition considers the pairs $(h, z)$ that don't satisfy the condition in part i) nor the conditions in part ii). The first inequality is given in (12) and results from imposing $u\left(U^{M}\right)>u\left(B^{M}\right)$, for agents who satisfy (8), and the second inequality is given in condition (14) and results from imposing $u\left(U T^{M}\right)>u\left(B^{M}\right)$, for agents who don't satisfy condition (8).

Figure 3 identifies the regions characterized above. Regions $A\left(A_{1}\right.$ and $\left.A_{2}\right)$ correspond to the set defined in Proposition 2, part iii), that is, correspond to those agents for whom the decision of sending their offspring to University depends on the value of $\phi$. These agents send their offspring to University if there is pure public funding of higher education but not if there is pure private funding. $A_{1}$ corresponds to those agents who don't need to pay private tutoring and region $A_{2}$ to those that do. 


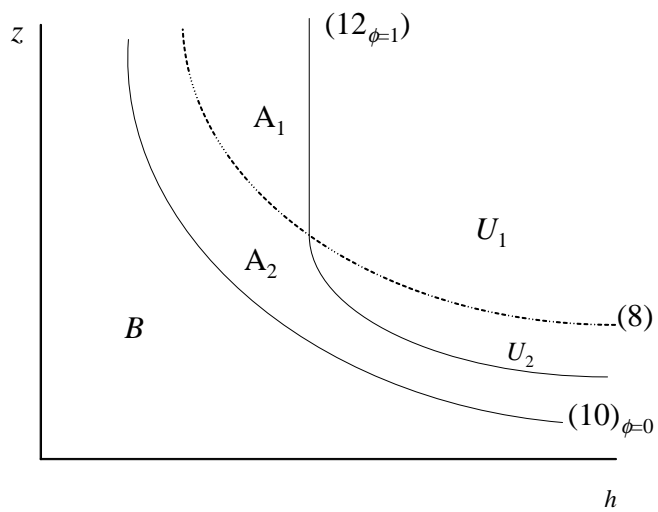

Figure 3: Access to higher education for different funding systems Regions $A_{1}$ and $A_{2}$ refer to agents for whom the decision of sending their offspring to University depend on $\phi$. Region $B$ refers to agents who never send their offspring to University and regions $U_{1}$ and $U_{2}$ refer to agents who always do.

As shown in Figure 2, access to the University increases when $\phi$ decreases. Thus, a government that wants to maximize access should choose $\phi=0$. But, as we saw this would not close the gap between rich and poor in the access to higher education, which is line with the empirical results of Carneiro and Heckman (2003) who defend that to reduce this gap countries need to invest in basic education.

This analysis emphasizes that only for a set of median agents - in terms of ability and income - does the decision of sending their offspring to higher education depend on the existence and depth of public funding of higher education. For the extremes of the population the value of $\phi$ does not change this decision.

However, even for those agents who gain access to University this does not imply that their welfare is higher under public funding of higher education as there are also costs associated with this funding system to be considered: taxes and, for those agents who need it, private tutoring. So, now I compare the level of utility under each funding system for each type of agent.

\section{Welfare: who gains, who loses?}

This section answers the question asked in the title of the paper, using the framework developed in the previous sections and beginning with the set of agents for whom access to higher education depends on the funding system. First, for each value of $\phi$, I look at the welfare of the marginal agent, where marginal refers to access, as defined below. Then, I extend the analysis to all agents whose decision depends on the value of $\phi$. Finally, I look at the agents in the extremes of the distribution. Proposition 8 summarizes the results: it characterizes the set of agents who have higher welfare under pure private funding than under a mixed system defined by a given value of $\phi$. 
Definition 3 For any $\phi \geq 0$, marginal agents are those who are indifferent between sending or not sending their offspring to higher education.

Lemma 4 looks at the welfare of the marginal agents for a given level of $\phi$ and compares welfare for that level of $\phi$, and for pure private funding, $(\phi=1)$.

Lemma 4 For any value of $\phi, \widetilde{\phi}$, such that $1>\widetilde{\phi} \geq 0$, the marginal agents have higher welfare under pure private funding of higher education, $\phi=1$, than with a system of mixed funding characterized by $\phi=\widetilde{\phi}$.

\section{Proof.}

i) For the marginal agents who satisfy condition (8), solutions of types $U$ and $B$ give the same utility and thus condition (12) is verified in equality. Thus, for those agents,

$$
\begin{aligned}
u\left(U^{M} ; \phi\right. & =\widetilde{\phi})=u\left(B^{M} ; \phi=\widetilde{\phi}\right) \Longleftrightarrow \\
& \Longleftrightarrow \ln \left(1-\tau_{\widetilde{\phi}}\right)(h-\widetilde{\phi} x)+\rho \ln \gamma h_{+1}^{B}=\ln \left(1-\tau_{\widetilde{\phi}}\right) h+\rho \ln h_{+1}^{B}
\end{aligned}
$$

And, for any $\tau>0$, it must be that,

$$
\ln \left(1-\tau_{\widetilde{\phi}}\right) h+\rho \ln h_{+1}^{B}<\ln h+\rho \ln h_{+1}^{B} \Longleftrightarrow u\left(B^{M}\right)<u\left(B^{R}\right)
$$

where the subscript $R$ refers to the solution in the context of pure private funding. Substituting with the previous condition we obtain that,

$$
u\left(U^{M}\right)<u\left(B^{R}\right)
$$

Thus, for these agents it is better not to go to the University and not to pay taxes; they have higher welfare for $\phi=1$.

ii) For the marginal agents who don't satisfy condition (8), solutions of types $U T$ and $B$ give the same utility and thus condition (14) is verified in equality. Thus, for those agents,

$$
\begin{aligned}
u\left(U T^{M} ; \phi\right. & =\widetilde{\phi})=u\left(B^{M} ; \phi=\widetilde{\phi}\right) \Longleftrightarrow \\
& \Longleftrightarrow \ln \left(1-\tau_{\widetilde{\phi}}\right)(h-e-\widetilde{\phi} x)+\rho \ln \gamma h_{+1}^{B}=\ln \left(1-\tau_{\widetilde{\phi}}\right) h+\rho \ln h_{+1}^{B}
\end{aligned}
$$

And, for any $\tau>0$, it must be that,

$$
\ln \left(1-\tau_{\widetilde{\phi}}\right) h+\rho \ln h_{t+1}^{B}<\ln h+\rho \ln h_{+1}^{B} \Longleftrightarrow u\left(B^{M}\right)<u\left(B^{R}\right)
$$

Substituting with the previous condition we obtain that,

$$
u\left(U T^{M}\right)<u\left(B^{R}\right)
$$

Thus, for these agents it is better not to go to the University and not to pay taxes nor tutoring; they have higher welfare for $\phi=1$. 
Consider those agents who would not go into University if the tuition was marginally higher. These are also agents for whom the utility from going into University is just marginally higher than the utility of not going. Thus, once they are obliged to pay taxes, it is their best choice to pay the remaining cost of higher education $\phi x$, or $\phi x+e$, and advance to University. However, if they could choose, they would always prefer not to go to University and not to pay taxes and tuition.

I now extend the result of the previous Lemma to a neighborhood of the set of marginal agents.

Proposition 5 For $\phi=\widetilde{\phi}$, such that $1>\widetilde{\phi} \geq 0$, consider the set of agents who send their offspring to higher education for $\phi=\widetilde{\phi}$ but not for $\phi=1$, that is these agents characterized by a pair $(h, z)$ such that,

$$
\begin{aligned}
h> & \frac{\widetilde{\phi} x \gamma^{\rho}}{\gamma^{\rho}-1} \cap z>\frac{\widehat{h}}{h^{\delta}}\left[\varepsilon \frac{\gamma^{\rho}-1}{\gamma^{\rho}} h+1-\varepsilon \widetilde{\phi} x\right]^{-1} \cap \\
& \cap\left(h<\frac{x \gamma^{\rho}}{\gamma^{\rho}-1} \cup z<\frac{\widehat{h}}{h^{\delta}}\left[\varepsilon \frac{\gamma^{\rho}-1}{\gamma^{\rho}} h+1-\varepsilon x\right]^{-1}\right)
\end{aligned}
$$

Let $\tau_{\widetilde{\phi}}<\left(\gamma^{\rho}-1\right) / \gamma^{\rho} .{ }^{17}$ There is a non-empty subset of this set of agents characterized by,

$$
\left\{\begin{array}{c}
h<\frac{\tilde{\phi} x \gamma^{\rho}}{\gamma^{\rho}-1 /\left(1-\tau_{\tilde{\phi}}\right)} \cup z<\frac{\widehat{h}}{h^{\delta}}\left[\varepsilon \frac{\gamma^{\rho}-1 /\left(1-\tau_{\tilde{\phi}}\right)}{\gamma^{\rho}} h+1-\varepsilon \widetilde{\phi} x\right]^{-1} \text { for } \widetilde{\phi}>0 \\
z<\frac{\widehat{h}_{t}}{h^{\delta}}\left[\varepsilon \frac{\gamma^{\rho}-1 /(1-\tau)}{\gamma^{\rho}} h+1\right]^{-1} \quad \text { for } \widetilde{\phi}=0
\end{array}\right.
$$

who have higher welfare for $\phi=1$ than for $\widetilde{\phi}$.

\section{Proof.}

i) Consider first those agents who satisfy conditions (15) and (8): these agents choose the solution of type $U$ for $\phi=\widetilde{\phi}$ and the solution of type $B$ under pure private funding. Thus, for these agents to have higher welfare for $\phi=1$ than for $\widetilde{\phi}$, it must be that,

$$
u\left(B^{R}\right)>u\left(U^{M} ; \phi=\widetilde{\phi}\right)
$$

Taking into account the solutions described in Table 2, this implies that

$$
\ln (h)+\rho \ln h_{+1}^{B}>\ln \left(1-\tau_{\widetilde{\phi}}\right)(h-\widetilde{\phi} x)+\rho \ln \gamma h_{+1}^{B}
$$

which implies the first inequality in condition (16), for $\widetilde{\phi}>0$. For $\widetilde{\phi}=0$, none of these agents have higher utility for $\phi=1$ than for $\widetilde{\phi}$.

\footnotetext{
${ }^{17}$ If this condition is not verified no student goes into higher education, as the productivity of higher education, as measured by $\gamma$, is too low.
} 
ii) Consider now those agents who satisfy condition (15) but don't satisfy condition (8): these agents choose the solution of type $U T$ for $\phi=\widetilde{\phi}$ and the solution of type $B$ under pure private funding. Thus, for these agents to have higher welfare for $\phi=1$ than for $\widetilde{\phi}$, it must be that,

$$
u\left(B^{R}\right)>u\left(U T^{M} ; \phi=\widetilde{\phi}\right)
$$

Taking into account the solutions described in Table 2, this implies that

$$
\ln (h)+\rho \ln h_{+1}^{B}>\ln \left(1-\tau_{\widetilde{\phi}}\right)(h-e-\widetilde{\phi} x)+\rho \ln \gamma h_{+1}^{B}
$$

Next, take into account the value of $e$ as determined in (5) and obtain,

$$
h>\left(1-\tau_{\widetilde{\phi}}\right) \gamma^{\rho}\left(h-\frac{\widehat{h}}{\varepsilon z h^{\delta}}+1-\widetilde{\phi} x\right)
$$

which, after some calculations, implies the second inequality in condition (16).

iii) To see that this set is non-empty compare the expressions in the right side of both inequalities in (16) with the corresponding expressions in the first line of (15). The curve defined in (16) is above the line defined by the first two inequalities in (15), for any $\tau>0$ and $\widetilde{\phi}>0$. For $\widetilde{\phi}=0$, the condition in (16) is above the corresponding expression in the first line of (15), for any $\tau>0$.

Moving from a pure private funding system to a mixed funding system always implies that there is a non-empty set of agents who gain access to higher education but whose welfare decreases. If everyone pays to fund higher education through income taxes, there are always some people for whom the increase in (their offspring') income obtained from going to the University is not enough to compensate their current consumption loss implied by taxes. For these people no taxes and no higher education would imply higher welfare. This is more probably the case for those agents who benefit less from going to University because of lower ability and/or lower parents' human capital. Figure 4 shows the set of agents who gain access to the University when the economy changes from a pure private funding system to a public funding system but that however, see their welfare decreased. Note that the lines defined by conditions (14) and (16) intersect for $h=x(1-\phi) \gamma^{\rho}(1-\tau) / \tau$, but both curves are always above condition (10) that defines the set of agents who never go to University. 

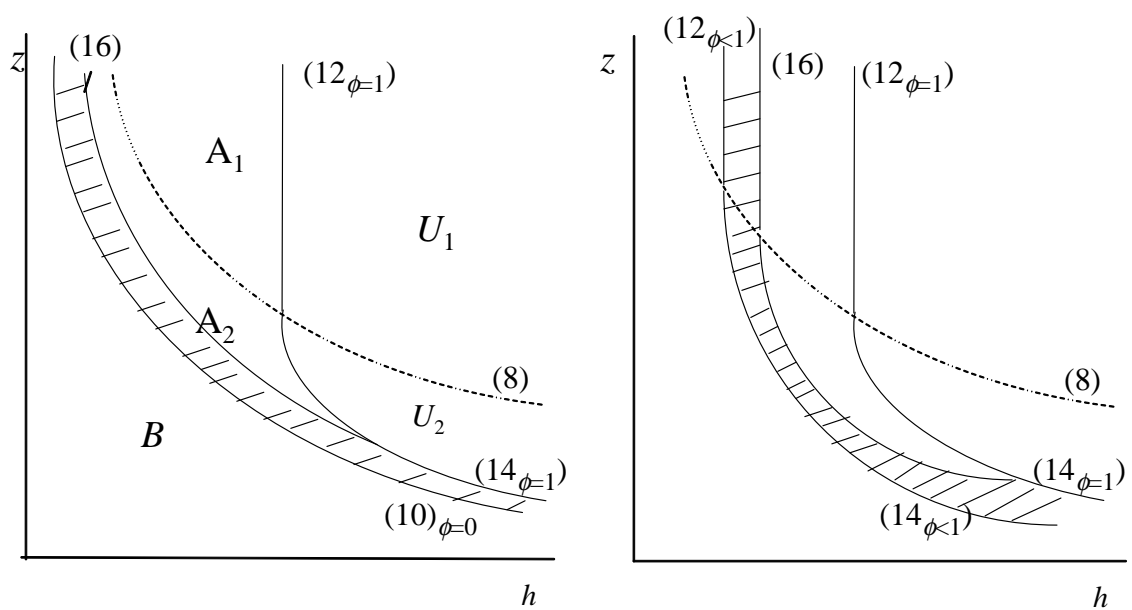

Figure 4: Agents who gain access to higher education but lose in welfare terms. The shaded areas refer to agents who gain access but whose welfare decreases. The left panel compares $\phi=1$ and $\phi=0$. The right one compares $\phi=1$ and $0<\widetilde{\phi}<1$.

Next, I look at welfare for the extremes of the distribution. The following Lemma looks at those agents who never send their offspring to the University whatever the funding system - region B in Figure 3.

Lemma 6 Those agents characterized in part i) of Proposition 2 don't send their offspring to the University in either funding system. All these agents have the highest welfare in the pure private funding system and their welfare decreases when $\phi$ increases.

Proof. Compare solutions of type B in Tables 1 and 2 and note that $\tau_{\phi}$ increases when $\phi$ decreases.

For those agents who don't send their offspring to University in any case, welfare is clearly higher under pure private funding of higher education. This happens because with public funding they have to pay taxes although they never use the higher education system. So, their preferred value of $\phi$ is 1 . This is just a consequence of the fact, already recognized in the literature, that public funding of higher education implies a redistribution from those that don't attend higher education to those that do. As students from high income families are more likely to attend higher education, this implies a redistribution of income from poor to rich people,

The next Lemma considers those agents who send their offspring to University in any funding system - regions $U_{1}$ and $U_{2}$ in Figure 3 - and compares welfare for pure private funding $(\phi=1)$ and a mixed funding system characterized by $\phi=\widetilde{\phi}$.

Lemma 7 Those agents characterized in part ii) of Proposition 2 send their offspring to the University for any value of $\phi$. These agents have higher welfare 
with $\phi=1$ than with $\phi=\widetilde{\phi}$, such that $1>\widetilde{\phi} \geq 0$ if,

$$
h>\frac{x}{\tau_{\widetilde{\phi}}}\left[1-\widetilde{\phi}\left(1-\tau_{\widetilde{\phi}}\right)\right] \cap z>\left[\frac{\widehat{h}}{h^{\delta}}\right]\left[\varepsilon h+1-\frac{\varepsilon x}{\tau_{\widetilde{\phi}}}\left[1-\widetilde{\phi}\left(1-\tau_{\widetilde{\phi}}\right)\right]\right]^{-1}
$$

\section{Proof.}

i) Consider first those agents characterized in part ii) of Proposition 2 who satisfy condition (8): these agents choose the solution of type $U$ for any $\phi$. Thus, for these agents to have higher welfare for $\phi=1$ than for $\widetilde{\phi}$, it must be that,

$$
u\left(U^{R}\right)>u\left(U^{M} ; \phi=\widetilde{\phi}\right)
$$

Taking into account the solutions described in Table 2, this implies that

$$
\ln (h-x)+\rho \ln h_{+1}^{U}>\ln \left(1-\tau_{\widetilde{\phi}}\right)(h-\widetilde{\phi} x)+\rho \ln h_{+1}^{U}
$$

which implies the first inequality in condition (17).

ii) Consider now those agents who don't satisfy condition (8): these agents choose the solution of type $U T$ for any $\phi$. Thus, for these agents to have higher welfare for $\phi=1$ than for $\widetilde{\phi}$, it must be that,

$$
u\left(U T^{R}\right)>u\left(U T^{M} ; \phi=\widetilde{\phi}\right)
$$

Taking into account the solutions described in Table 2, this implies that

$$
\ln (h-x)+\rho \ln h_{+1}^{U}>\ln \left(1-\tau_{\widetilde{\phi}}\right)(h-e-\widetilde{\phi} x)+\rho \ln h_{+1}^{U}
$$

Next, take into account the value of $e$ as determined in (5) and obtain, after some calculations, the second inequality in condition (17).

For those agents who always send their offspring to the University without the need to pay tutoring welfare may be higher under pure private funding than under a partial public funding of higher education depending on their level of income. This happens because with public funding (partial or total) they have to pay taxes, which are proportional to income, but they only pay part of the fixed University tuition while under private funding the opposite happens. As taxes are proportional to income, the richer pay more taxes and if they are rich enough they prefer to pay the tuition. So, the richer they are, the more likely they are to prefer pure private funding.

Those agents who always send their offspring to University but that need to pay private tutoring spend the same amount with tutoring in both funding systems. However, as I consider these expenditures to be tax deductible this must be taken into account when comparing taxes and University tuition. Tax deductions are higher for those agents whose offspring are further away from 
the threshold value, $\widehat{h}$. Thus, for those agents who pay private tutoring, the higher their level of human capital, and the higher the ability of their offspring, the more they prefer private funding because, as they spend a smaller amount in private tutoring, their tax deductions are also smaller.

Proposition 8 summarizes the results of the previous Lemmas and Proposition 5 .

Proposition 8 Let $\tau_{\phi}<\left(\gamma^{\rho}-1\right) / \gamma^{\rho}$. Those agents characterized by a pair $(h, z)$ such that,

$$
\begin{gathered}
\left(h>\frac{x}{\tau_{\phi}}\left[1-\widetilde{\phi}\left(1-\tau_{\phi}\right)\right] \cap z>\frac{\widehat{h}}{h^{\delta}}\left[\varepsilon h+1-\frac{\varepsilon x}{\tau_{\phi}}\left[1-\widetilde{\phi}\left(1-\tau_{\phi}\right)\right]\right]^{-1}\right) \cup \\
\left\{\begin{array}{c}
h_{t}<\frac{\widetilde{\phi} x \gamma^{\rho}}{\gamma^{\rho}-1 /\left(1-\tau_{\tilde{\phi}}\right)} \cup z<\frac{\widehat{h}}{h^{\delta}}\left[\varepsilon \frac{\gamma^{\rho}-1 /\left(1-\tau_{\tilde{\phi}}\right)}{\gamma^{\rho}} h+1-\varepsilon \widetilde{\phi} x\right]^{-1} \text { for } \widetilde{\phi}>0 \\
z<\frac{\widehat{h}_{t}}{h^{\delta}}\left[\varepsilon \frac{\gamma^{\rho}-1 /(1-\tau)}{\gamma^{\rho}} h+1\right]^{-1} \quad \text { for } \widetilde{\phi}=0
\end{array}\right.
\end{gathered}
$$

have higher welfare for $\phi=1$ than for $\phi=\widetilde{\phi}$.

Proof. The conditions in the first line were obtained in Lemma 7, the conditions in the second line were obtained in Proposition 5. From Lemma 6 we know that all agents characterized by pairs $(h, z)$ that are below the line determined in condition (10) have higher welfare for $\phi=1$. Any pair $(h, z)$ that verifies the conditions in the second line is also below the line defined in condition (10). Thus, for all these agents welfare is higher for $\phi=1$ than for $\phi=\widetilde{\phi}$.

Figure 5 shows the set of agents who have higher welfare under pure private funding than under pure public funding, as implied by the previous Proposition, for $\widetilde{\phi}=0$. Note that, for $\phi=0$, the lines defined by conditions (14), (17) and (16) intersect for $h=x \gamma^{\rho}(1-\tau) / \tau$, but the three curves are always above condition (10) that defines the set of agents who never go to University.

From the analysis until now, I conclude that although a change from a pure private funding system to a pure public funding system, or more generally to a mixed funding system, always implies an increase in access to higher education, the richer and the poorer prefer private funding and the middle income agents prefer public funding. Moreover, we can not identify gaining access to University with an increase in welfare. This happens because on one hand, access to higher education increases welfare but on the other hand the fact there is public funding of higher education implies that all agents have to pay higher taxes, which decreases welfare. For the agents identified in Proposition 5 the last effect is stronger than the first one. 


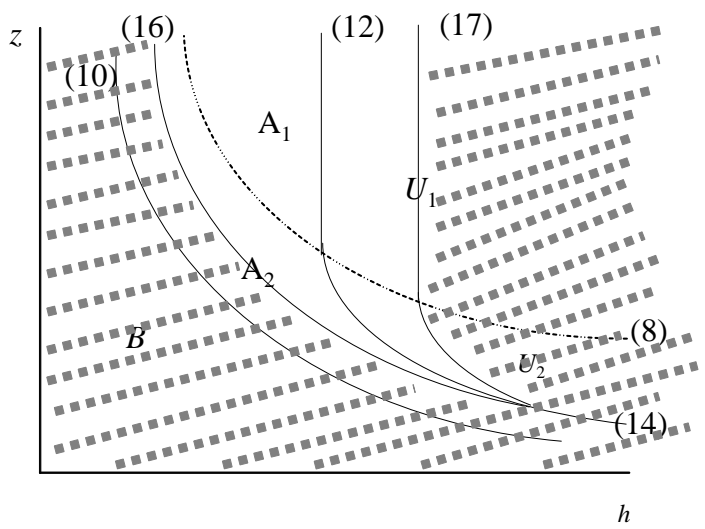

Figure 5: higher welfare with private than with public funding The shaded area corresponds to agents who have higher welfare with pure private funding than with pure public funding. The white area in the middle corresponds to agents who prefer pure public funding.

A new and important result is that among those who gain access to the University with public funding the poorer among them prefer pure private funding. Thus, when we compare public funding with pure private funding, once we take into account the possibility of complementing public funding of basic education with private tutoring, there is always a set of agents among those who gain access to the University that would have higher welfare without going to the University and without paying taxes and private tutoring. Note that paying private tutoring is an optimal choice for these agents only because they have to pay taxes to fund higher education anyway.

\section{A Different Funding System: higher educa- tion tax}

Lemma 4 states that with public funding - even partial public funding - of higher education, the marginal agent to access higher education would have higher welfare with a pure private funding system. He would prefer not to send his offspring to University and not to pay taxes. Lemma 6 states that all those who don't send their offspring to higher education in any system prefer pure private funding as when there is public funding of higher education they pay for the higher education of the others. To avoid these problems I now consider a funding system for higher education where agents only contribute for higher education funding if they send their offspring to University. So, agents may choose if they want to be part of the higher education (funding) system. I consider a mixed system similar to the previous one, where $\phi$ measures the private contribution for higher education costs but where only those who send their offspring to University pay the taxes that finance higher education. ${ }^{18}$ This

${ }^{18}$ All taxes are used to fund higher education, I abstract from other uses of public revenues. 
is a "higher education tax" as it is only paid by those who "use" the higher education system. This also approximates a system where tuition is fixed but there are simultaneously grants that depend on income on such a way that the final amount paid by each agent for higher education depends positively on the households' income. ${ }^{19}$

In this environment there are the same three types of solutions: $U$ when the student goes into University without the need of private tutoring, UT when the student goes to University but for that needs to pay private tutoring and $B$ when the student doesn't go to University. The next table characterizes these solutions, where the subscript $O$ stands for a solution in this context where the agent may opt for University and paying taxes or not going to University and not paying taxes. $\tau_{\phi_{O}}$ is the tax rate associated to a private contribution $\phi x$ in this funding system.

Table 3: solutions with a "higher education" tax

\begin{tabular}{|llll|}
\hline & $U^{O}$ & $U T^{O}$ & $B^{O}$ \\
$c$ & $\left(1-\tau_{\phi_{O}}\right)(h-\phi x)$ & $\left(1-\tau_{\phi_{O}}\right)(h-e-\phi x)$ & $h$ \\
$h_{+1}$ & $h_{+1}^{U}=\gamma h_{+1}^{B}$ & $h_{+1}^{U}=\gamma h_{+1}^{B}$ & $h_{+1}^{B}$ \\
\hline
\end{tabular}

In this context, if condition (8) is satisfied, that is, if the agent doesn't need to pay private tutoring, the agent chooses between solutions $U$ and $B$. The choice is not obvious even if $\phi=0$, as he only pays taxes if his offspring goes to University. Comparing $U^{O}$ and $B^{O}$, we obtain that agents for whom condition (8) is verified send their offspring to University if:

$$
u\left(U^{O}\right)>u\left(B^{O}\right) \Longleftrightarrow h>\phi x \frac{\gamma^{\rho}}{\gamma^{\rho}-1 /\left(1-\tau_{\phi_{O}}\right)}
$$

where I assume that $\tau_{\phi_{O}}<\left(\gamma^{\rho}-1\right) / \gamma^{\rho} .^{20}$

For those agents for whom condition (8) is not satisfied, that is, for those agents who need to pay private tutoring, we compare solutions $U T^{O}$ and $B^{O}$. Taking into account the value of tutoring as defined in (5) we obtain that these agents send their offspring to University if,

$$
u\left(U T^{O}\right)>u\left(B^{O}\right) \Longleftrightarrow z>\frac{\widehat{h}}{h^{\delta}}\left[\varepsilon \frac{\gamma^{\rho}-1 /\left(1-\tau_{\phi_{O}}\right)}{\gamma^{\rho}} h+1-\varepsilon \phi x\right]^{-1}
$$

Figure 6 shows the regions that correspond to each type of solution. ${ }^{21}$ Condition (19) defines a line that crosses (8) at the level of $h$ defined in (18).

\footnotetext{
${ }^{19}$ This funding system could also approximate, in the context of this paper, the incomecontingent student loans recently introduced in UK, and with variants, already implement for some years in Australia, New Zealand and Sweden among other countries. However, here taxes are paid by parents while their children are at University.

${ }^{20}$ Again, if $\tau_{\phi_{O}}>\left(\gamma^{\rho}-1\right) / \gamma^{\rho}$ no agent goes to University.

${ }^{21}$ Here it is not clear what happens to access when $\phi$ changes, as change on $\tau_{\phi_{O}}$ has opposite effects on access. See conditions (18) and (19).
} 
(a) $\phi=0$

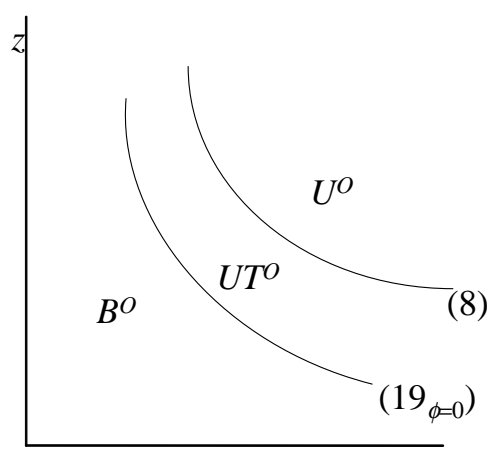

$h$ (b) $\phi>0$

(18)

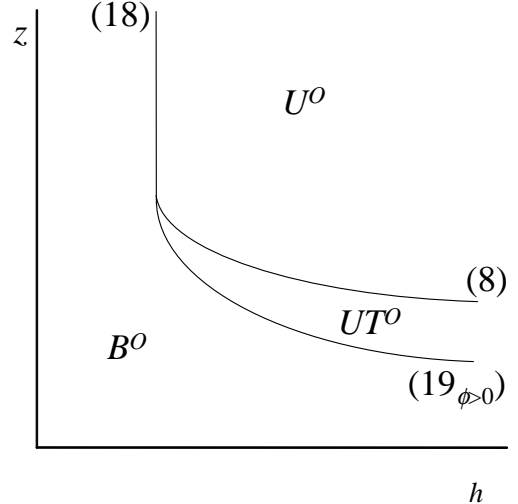

Figure 6: Agents' choices under a higher education tax

$U^{o}$ refers to agents who send their offspring to the University without tutoring, $U T^{o}$ refers to agents who pay for tutoring and $B^{o}$ refers to agents who don't send their offspring to the University.

The following Proposition compares access to higher education for a given value of the tuition, determined by $\phi$, when public expenditures are financed with a higher education tax or by an income tax applied to the whole population as described in the previous sections.

Proposition 9 For any $\phi=\widetilde{\phi}$, such that $1>\widetilde{\phi} \geq 0$, for the same value of $\widetilde{\phi}$, there are more students continuing to higher education when all taxpayers contribute to the funding system than when only those with offspring in higher education contribute to the funding system.

Proof. For $\phi=0$, condition (19) is always above condition (10). For $0<\phi<1$, condition (19) is always above condition (14) and condition (18) is always to the right of condition (13).

As we would expect, if going to University implies paying taxes, access to higher education is lower for the same value of tuition, for $\phi<1$, than in the system where all agents contribute through taxes to the public funding of higher education. This is shown in Figure 7. For $\phi=1$, there is pure private funding exactly as before: no taxes and those agents who send their offspring to higher education pay the whole cost $x$. Thus, for $\phi=1$, all the results are exactly as in Sections 3 and 4. 


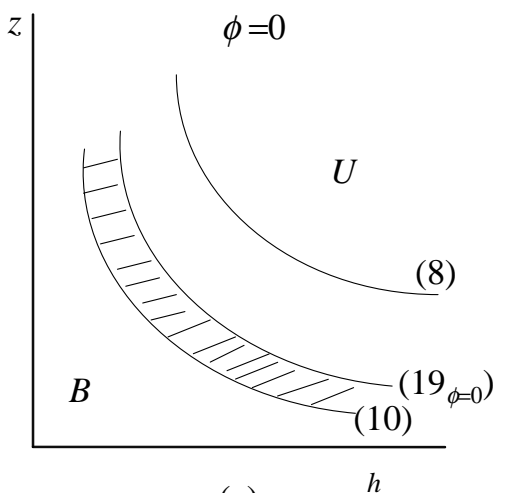

(a)

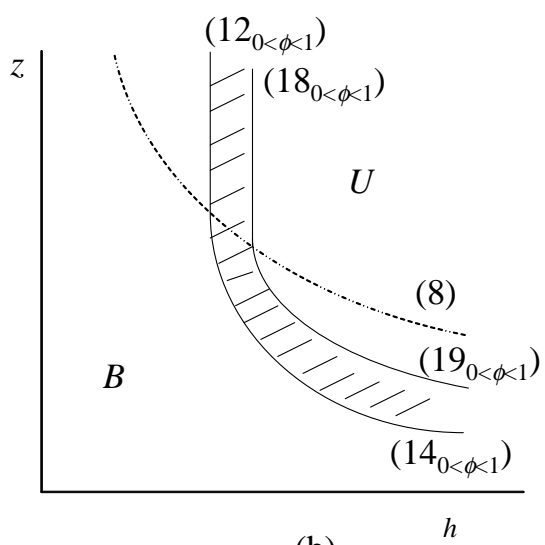

(b)

Figure 7: Access to higher education under a higher education tax and with a generic income tax

The shaded area corresponds to agents who send their offspring to University when all taxpayers contribute to the public funding of higher education but not when only those who benefit from the system contribute to it, considering the same value for $\phi$. Panel (a) is for $\phi=0$, panel (b) is for $0<\phi<1$.

The following Proposition looks at the welfare of those agents for whom access to higher education depends on the value of $\phi$, for the case of a higher education tax.

Proposition 10 If taxes are paid only by those agents who send their offspring to higher education, then, for any $\phi=\widetilde{\phi}$, such that $1 \gtrsim \widetilde{\phi} \geq 0$, all those agents who send their offspring to higher education for $\phi=\widetilde{\phi}$ but not for $\phi=1$ have higher welfare for $\phi=\widetilde{\phi}$ than for $\phi=1$.

\section{Proof.}

i) Consider first those agents who satisfy condition (8): if send their offspring to higher education for $\phi=\widetilde{\phi}$ but not for $\phi=1$, then they choose the solution of type $U$ for $\phi=\widetilde{\phi}$ and the solution of type $B$ under pure private funding. Thus, for these agents, it must be that,

$$
u\left(B^{R}\right)>u\left(U^{R}\right) \quad \text { and } \quad u\left(U^{O} ; \phi=\widetilde{\phi}\right)>u\left(B^{O} ; \phi=\widetilde{\phi}\right)
$$

From Table 2, solutions $B^{R}$ and $B^{O}$ coincide. Thus $u\left(B^{O} ; \phi=\widetilde{\phi}\right)=$ $u\left(B^{R}\right)$. So, we obtain that $u\left(U^{O} ; \phi=\widetilde{\phi}\right)>u\left(B^{R}\right)$, implying that these agents have higher welfare for $\phi=\widetilde{\phi}$ than for $\phi=1$.

ii) Consider now those agents who don't satisfy condition (8): these agents choose the solution of type $U T$ for $\phi=\widetilde{\phi}$ and the solution of type $B$ under pure private funding. Thus, it must be that, for these agents,

$$
u\left(B^{R}\right)>u\left(U T^{R}\right) \quad \text { and } \quad u\left(U T^{O} ; \phi=\widetilde{\phi}\right)>u\left(B^{O} ; \phi=\widetilde{\phi}\right)
$$


We saw that $u\left(B^{O} ; \phi=\widetilde{\phi}\right)=u\left(B^{R}\right)$. Thus, $u\left(U T^{O} ; \phi=\widetilde{\phi}\right)>u\left(B^{R}\right)$, implying that these agents have higher welfare for $\phi=\widetilde{\phi}$ than for $\phi=1$.

The main advantage of having taxes paid only by those agents who send their offspring to higher education is that with this system there is no longer a redistribution of income from the poorer to the richer. Moreover, in this case, welfare increases for all those agents who gain access to higher education depends on public funding..

\section{Conclusion}

This paper studies the effect of public funding of higher education on the welfare of different agents, focusing on those agents whose decision of sending or not their children to the University depends on public funding policy. The model considers that all decisions are made by parents and takes into account the hierarchical nature of the educational system and also the fact that parents always have the possibility to complement basic public education with private expenditures in individual tutoring.

Assuming that public expenditure on higher education is financed through a proportional income tax applied to the whole adult population, I consider three funding systems for higher education: pure public funding, pure private funding and a mixed funding system, where only a percentage $\phi$ of the higher education cost is privately supported with the remaining being publicly supported. I obtain that although pure public funding maximizes access to University, moving from pure private funding, to pure public funding or to a mixed funding system, always decreases the welfare of the poorer agents. Moreover, I show that, for any value of $\phi$, the welfare of the marginal agents to access University is always lower than under a pure private funding system. This happens because in the pure private funding system these parents would not send their offspring to University but they would also not pay the tuition nor taxes. Thus, when studying the welfare effects of public funding for higher education, we can not identify gaining access to University with an increase in welfare. The equality of opportunity in access to higher education is the main argument in favor of public funding of higher education. However, it is shown that if all taxpayers contribute to the public funding of higher education then the system is harming those agents who it was supposed to help.

Finally, I consider financing higher education through a higher education tax, meaning that only those who send their children to University contribute to the public funding of higher education. With this funding system, although access decreases relative to the case where all agents contribute to the system, it is shown that all agents who gain access to higher education due to public funding have higher welfare under public funding than with pure private funding. In this case, all income redistribution happens in the right direction and the system increases the welfare of those agents it is supposed to help. 
I did not consider the effects of current policy on future human capital and aggregate productivity. This would be an interesting extension. However, for the current generation I believe that the analysis in this paper is the most relevant one. Note that, in this paper, the utility of agents already increases with the education of their children, so it is already considered some degree of intergenerational altruism.

Also, I did not consider any specific distribution of human capital and ability. This implies that the results obtained are valid for any possible distribution of human capital and ability and thus, for any economy.

An important policy implication that results from the analysis in this paper is that funding higher education with a generic tax income that applies to everyone in the economy, including people that don't use the higher education system reduces welfare for those people and also for those that gain access to higher education but for whom the benefit in terms of income change is small. And these tend to be the students with poor earlier educational achievements.

\section{References}

[1] Barr, Nicholas "Higher Education Funding" Oxford Review of Economic Policy 20 (2) (2004): 264-283

[2] Birdsall, Nancy "Public Spending on Higher Education in Developing Countries: Too Much or Too Little?" Economics of Education Review 15 (1996): 407-419

[3] Blankenau, W. "Public schooling, college subsidies and Growth" Journal of Economic Dynamics and Control 29 (2005): 487-507

[4] Cardak, B. and Chris Ryan "Participation in Higher Education in Australia: Equity and Access" The Economic Record, The Economic Society of Australia, vol. 85(271), (December 2009): 433-448

[5] Carneiro, Pedro and Heckman, James J. "The Evidence on Credit Constraints on Post-Secondary Schooling" The Economic Journal 112 (October) (2002): 989-1018

[6] Carneiro, Pedro and Heckman, James J. "Human Capital Policy" in Heckman J. and Krueger A. Inequality in America: What Role for Human Capital Policies? Cambridge MA, MIT Press (2003)

[7] Caucutt, E. and Kumar, K. "Higher education subsidies and heterogeneity: a dynamic analysis." Journal of Economic Dynamics and Control 27 (2003): $1459-1502$

[8] Creedy, J. and François, P. "Financing Higher Education and Majority Voting." Journal of Public Economics 43 (1990): 181-200 
[9] de la Croix, David and Doepke, Matthias "Public versus private education when differential fertility matters" Journal of Development Economics 73 (2004): 607-629

[10] De Fraja, Gianni, "The Design of Optimal Education Policies" Review of Economic Studies 69 (2002): 437-466

[11] Epple, Dennis and Romano, Richard E. "Public Provision of Private Goods" Journal of Political Economy 104 (Feb 1996) 57-84

[12] Epple, Dennis and Romano, Richard E. "Competition between Private and Public Schools, Vouchers and Peer-Group Effects" American Economic Review 88 (1998) 33-62

[13] Fernández, Raquel and Rogerson, Richard. "On the Political Economy of Education Subsidies." Review of Economic Studies 62 (April 1995): 249-62

[14] Galor, Oded and Zeira, Joseph "Income Distribution and Macroeconomics" Review of Economic Studies 60 (1993): 35-52

[15] Gloom, Gerhard and Ravikumar, B. "Public versus private investment in human capital: endogenous growth and Income Inequality" Journal of Political Economy 100 (1992): 818-834

[16] Gloom, Gerhard and Ravikumar, B. "Public education and Income Inequality" European Journal of Political Economy 19 (2003): 289-300

[17] Greenway, David and Haynes, Michelle, "Funding Higher Education" in G. Johnes and J. Johnes (eds.) International Handbook of the Economics of Education, Edward Elgar Publishing (2004)

[18] Hansen, W. Lee, and Burton A. Weisbrod. "The Distribution of Costs and Direct Benefits of Public Higher Education: The Case of California." Journal of Human Resources 4(2) (1969):176-191.

[19] Judson, Ruth. "Economic Growth and Investment in Education: How Allocation Matters." Journal of Economic Growth 3 (December 1998): 361-384

[20] OECD, Education at a Glance 2009

[21] Su, Xuejuan. "The allocation of public funds in a hierarchical educational system." Journal of Economic Dynamics and Control 28 (2004): 2485-2510

[22] Wo $\beta$ mann, Ludger and Schutz, Gabriela "Efficiency and Equity in European Education and Training Systems" Analytical Report for the European Commission prepared by EENEE (2006) 